\title{
Strength Deterioration of Concrete in Sulfate Environment: An Experimental Study and Theoretical Modeling
}

\author{
Yingwu Zhou, Hao Tian, Lili Sui, Feng Xing, and Ningxu Han \\ Guangdong Provincial Key Laboratory of Durability for Marine Civil Engineering, Shenzhen University, Shenzhen 518060, China \\ Correspondence should be addressed to Lili Sui; suill8969@163.com
}

Received 11 March 2015; Revised 21 June 2015; Accepted 22 June 2015

Academic Editor: Rui Vilar

Copyright (C) 2015 Yingwu Zhou et al. This is an open access article distributed under the Creative Commons Attribution License, which permits unrestricted use, distribution, and reproduction in any medium, provided the original work is properly cited.

\begin{abstract}
Sulfate corrosion is one of the most important factors responsible for the performance degradation of concrete materials. In this paper, an accelerated corrosion by a sulfate solution in a dry-wet cycle was introduced to simulate the external sulfate corrosion environment. The deterioration trend of concrete strength and development law of sulfate-induced concrete corrosion depth under sulfate attacks were experimentally studied. The damaged concrete section is simply but reasonably divided into uncorroded and corroded layers and the two layers can be demarcated by the sulfate corrosion depth of concrete. The accelerated corrosion test results indicated that the strength degradation of concrete by sulfate attack had a significant relation with the corrosion depth. Consequently, this paper aims to reveal such relation and thus model the strength degradation law. A large amount of experimental data has finally verified the validity and applicability of the models, and a theoretical basis is thus provided for the strength degradation prediction and the residual life assessment of in-service concrete structures under sulfate attacks.
\end{abstract}

\section{Introduction}

Because of the long-term exposure of concrete structures to various natural corrosive environments, various corrosive substances in these environments are constantly transported into concrete, causing the expansion, cracking, spalling, and finally performance degradation of concrete, such as the strength, dynamic elastic modulus, and surface hardness. Among the numerous corrosive substances, sulfates are the most destructive corrosive substance. It is one of the important factors influencing the durability of concrete [1].

Recently, existing studies on the corrosion mechanism of concrete by sulfates mainly focused on the permeation of sulfate ions in concrete and the chemical reactions of sulfates with the composition of concrete [2-11]. For example, the diffusion and reactions of corrosive substances in concrete have been studied [2-6], and both the performance deterioration of corroded concrete and the diffusion properties of the corrosive substances in concrete have been evaluated. The development trend of concrete's expansion rate under various environmental conditions was experimentally investigated
[7-9], and thus an expansion-rate prediction model was developed. These studies have evaluated the process and capacity of sulfate corrosion resistance by concrete mainly at the material level; however, the relationship with concrete strength at the macrolevel has not been established. The strength of concrete is an important mechanical performance index of concrete as a structural/functional material. The deterioration trend of concrete strength under sulfate corrosion is an essential basis for the residual life prediction of concrete structures. Existing studies indicate that sulfate ions in the environment chemically react with the internal composition of concrete by entering into the concrete through diffusion, convection, capillary adsorption, and other processes to generate expansive products such as ettringite, gypsum [12-14], and sodium sulfate crystals when concrete is corroded by sulfate solution in dry-wet cycle. The expansive products continuously fill the internal pores of concrete, thus making the concrete more compact with slightly improved concrete strength. Therefore, the early stage of corrosion increases the strength of concrete. With the expansive products continuous contact with the pore wall of 
concrete, expansive stresses are gradually generated. When the magnitude of the stress eventually exceeds the tensile strength of concrete, the concrete cracks, accompanied by the loss of tobermorite, the primary hydration product of concrete [10]; the concrete then enters a degradation stage and undergoes strength deterioration.

Therefore, some experimental studies have been performed on the degradation trend of concrete strength under various sulfate corrosion environments [15-20], and either corrosion resistance coefficient, defined as the ratio of the strength of corroded concrete to that of uncorroded concrete, or corrosion strength rate, defined as the ratio of the strength loss of corroded concrete to the strength of uncorroded concrete, was introduced to characterize the strength degradation of corroded concrete [21-24]. For example, Zhang et al. [22] developed a model for corrosion resistance coefficient of concrete during sulfate attacks; Shazali et al. [23] proposed a complex model of local strength-loss levels at various depths from exposure surface; Schneider and Chen [24] established a time varying empirical model for the corrosion resistance coefficient of concrete; Song and Cheng [25] used the change in ultrasonic velocity to characterize the strength loss of corroded concrete. The relationship between the change in ultrasonic velocity and the water-cement ratio, concentration of corrosion solution, and time of corrosion was derived. The above studies have explained the degradation damage of concrete by sulfates at the macromechanical level and can be used as a beneficial supplement to the above analysis performed at the micromaterial level. However, most of them have never derived or interpreted the macrostrength deterioration of concrete from its degradation at the micromaterial level.

The corrosion of concrete by sulfates is a gradual process that starts from the surface layer to the core. The development trend of concrete corrosion depth by sulfates, which depends on the diffusion, transport, and chemical reactions of sulfate ions in the microstructure of concrete, can directly reflect the evolution of the microdamage of concrete materials and thus quantitatively characterize the corrosion degree of concrete by sulfates. It is believed to be significantly related to the strength deterioration of concrete and to be a bridge to link the microdamage of concrete materials with the macrostrength deterioration of concrete. So far, none of the existing studies have tried to establish a relationship between the strength deterioration of concrete and sulfate-induced corrosion depth. This paper aims to fill the gap. In this study, an experimental method was developed for the accelerated corrosion by a sulfate solution in a dry-wet cycle to study the strength deterioration trend of concrete under sulfate corrosion. The strength and corrosion depth of concrete after various corrosion periods were measured. The sulfateinduced corrosion depth based strength deterioration models of concrete were established. As the corrosion depth of concrete by sulfates can be easily obtained by any nondestructive testing method such as the ultrasonic testing technique [26, 27], the research findings can provide a reference basis for the strength analysis and prediction of concrete structures after sulfate corrosion in practical engineering.
TABLE 1: Mineral constituents and contents of cement.

\begin{tabular}{lcccc}
\hline Constituent & $\mathrm{C}_{3} \mathrm{~S}$ & $\mathrm{C}_{2} \mathrm{~S}$ & $\mathrm{C}_{3} \mathrm{~A}$ & $\mathrm{C}_{4} \mathrm{AF}$ \\
\hline Content (\%) & 59.10 & 15.99 & 8.74 & 12.71 \\
\hline
\end{tabular}

TABLE 2: Design of concrete mix proportion $\left(\mathrm{kg} / \mathrm{m}^{3}\right)$.

\begin{tabular}{lcccc}
\hline Material & Water & Cement & Sand & Gravel $(5 \sim 25 \mathrm{~mm})$ \\
\hline Dose & 200 & 417 & 638 & 1125 \\
Proportion & 0.48 & 1 & 1.53 & 2.70 \\
\hline
\end{tabular}

\section{Experimental Studies on the Corrosion of Concrete by Sulfates}

In this study, an experimental method was developed for the accelerated corrosion by a sulfate solution in a dry-wet cycle to study the strength deterioration mechanism of concrete due to sulfate attacks. The specific experimental method will be described systematically in this section.

2.1. Design of Concrete Composition. To maximally reduce the effect of concrete's own strength development on its late-stage degradation, no slag, fly ash, or other admixtures were added during the manufacturing of concrete. The Japanese Onoda PII52.5 pure Portland cement was used in the preparation of concrete with a water-cement ratio of 0.48 . The mineral constituents of Japanese Onoda PII52.5 pure Portland cement are listed in Table 1. The composition of the concrete is shown in Table 2, where high quality natural quartz sand with a fineness modulus of 3.1 and a gradation of $0.16-5 \mathrm{~mm}$ and granite gravel with a gradation of $2-25 \mathrm{~mm}$ were used to cast the concrete. The experimental samples were cubes of $150 \mathrm{~mm}$ in side length and were cured under standard conditions for 28 days. Three concrete cubes were used to test the average compressive strength of the concrete, and the average 28-day compressive strength was 56.1 MPa.

2.2. Scheme of Accelerated Sulfate Corrosion Test. In this paper, the artificial accelerated corrosion by a sulfate solution in a dry-wet cycle was designed to simulate the typical marine sulfate corrosion environment. The highest temperature (local temperature) was set as $40^{\circ} \mathrm{C}$, and the dry-wet cycling period was defined as $12 \mathrm{~h}$. The detailed information of the artificial accelerated corrosion is given in Table 3. It should be noted that as the diffusion of sulfate ion in concrete is a slow process (as verified in Table 4 that it only diffused $27.5 \mathrm{~mm}$ from exposure surface of concrete to the core after 150 days' corrosion), the dry process is designed to be 3 hours just to ensure the complete dryness of the corrosion layer of the concrete based on a trial test.

The corrosion times were defined as $0,30,60,90,120$, and 150 days. Four identified concrete samples were designed at each corrosion time, of which three were used to test the strength variations due to sulfate corrosion and the remaining one was used to scan the microstructure change of the concrete and measure the distribution of sulfate irons from exposure surface to the core. Therefore, a total of 24 samples were constructed. All the concrete samples were placed in 


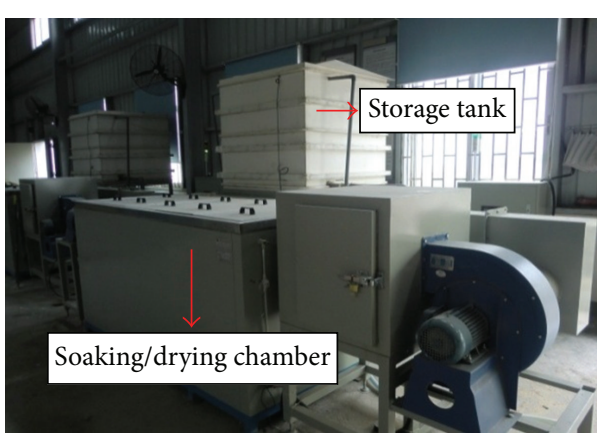

(a) Climate-simulation corrosion test chamber

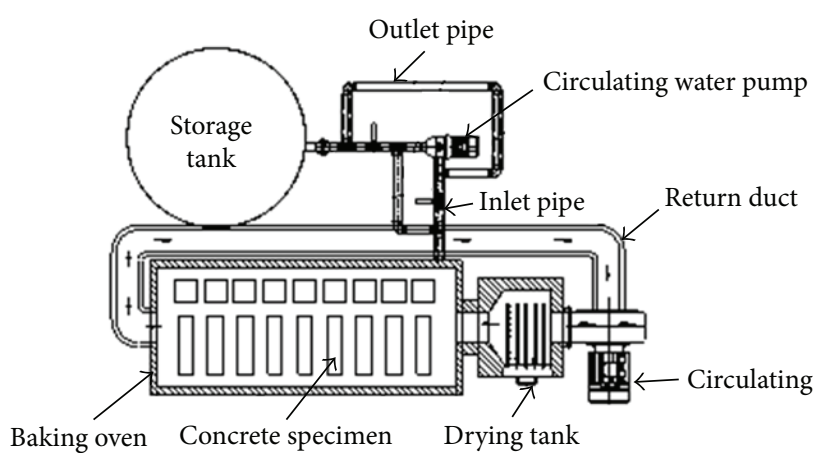

(b) Principles of corrosion test chamber: plane view

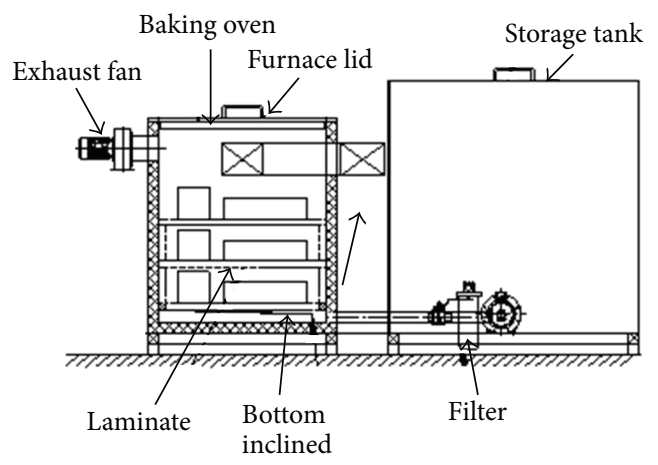

(c) Principles of corrosion test chamber: sectional view

FIGURE 1: Equipment and schematic diagram of dry-wet cycling experiment.

TABLE 3: System of dry-wet cycling test.

\begin{tabular}{ll}
\hline Cycling process & Specific parameters \\
\hline \multirow{3}{*}{ Soaking } & $\begin{array}{l}\text { Soaked in } 7 \% \text { sodium } \\
\text { sulfate solution for } 9 \mathrm{~h} \text { at } \\
\end{array}$ \\
$25^{\circ} \mathrm{C}$ \\
Drying at room temperature & $\begin{array}{l}\text { Dried for } 1 \mathrm{~h} \text { at room } \\
\text { temperature }\end{array}$ \\
Baking at high temperature & Backed for $1 \mathrm{~h}$ at $40^{\circ} \mathrm{C}$ \\
Natural cooling & Naturally cooled for $1 \mathrm{~h}$ \\
\hline
\end{tabular}

TABLE 4: Corrosion depth of concrete and its corresponding average strength at each corrosion time.

\begin{tabular}{lccccc}
\hline Corrosion time (day) & 30 & 60 & 90 & 120 & 150 \\
\hline Corrosion depth (mm) & 12.5 & 17.5 & 20 & 22.5 & 27.5 \\
Average strength (MPa) & 58.2 & 59.7 & 53.6 & 46.2 & 31.9 \\
\hline
\end{tabular}

a professionally designed climate-simulation corrosion test chamber with two containers (i.e., a storage tank and soaking/drying chamber (Figure 1(a))). A solution injection and discharge circulation system, hot-air circulation system, and system control chamber were provided. Various parameters of the dry-wet cycle were all automatically controlled by the system control chamber. An accurate control system and precise test instruments were provided to ensure the set temperature and humidity. The schematic control diagrams are shown in Figures 1(b) and 1(c).
The working principles of the dry-wet cycling test chamber are as follows: in the soaking process, the solution was injected from the storage tank to the drying chamber via the solution circulation system to ensure that all the samples were completely immersed in sulfate solution. After completing the soaking process, the machine automatically transferred the solution in the drying chamber back to the storage tank, thus draining the residual solution in the drying chamber, and to keep the concentration after each cycle, the solution was replaced daily or every two cycles. In the drying process, the temperature of the drying chamber can be controlled between 30 and $120^{\circ} \mathrm{C}$, with an error of $\pm 3^{\circ} \mathrm{C}$. To make sure that the temperature field in the drying chamber is uniform during the drying, the heating mode by hot-air circulation is designed in the system to avoid the problem of cold corners commonly encountered in the traditional heating mode by a tubular electric heating element. Figure 1(b) shows the schematic drawing of the hot-air circulation system, which consists of a drying box and circulating fan. As the extent of drying can significantly affect the degradation rate of concrete, it is extremely important to control the humidity by the properly designed abovementioned heat system in the drying process. Moreover, some functions were added in the design process of the dry-wet cycling testing machine to better satisfy these requirements: (1) the entire process can be controlled by the embedded functional chips, and various cycling processes can be controlled automatically by the programs; (2) the total number of cycles at each corrosion time can be automatically recorded; (3) a power-off memory 


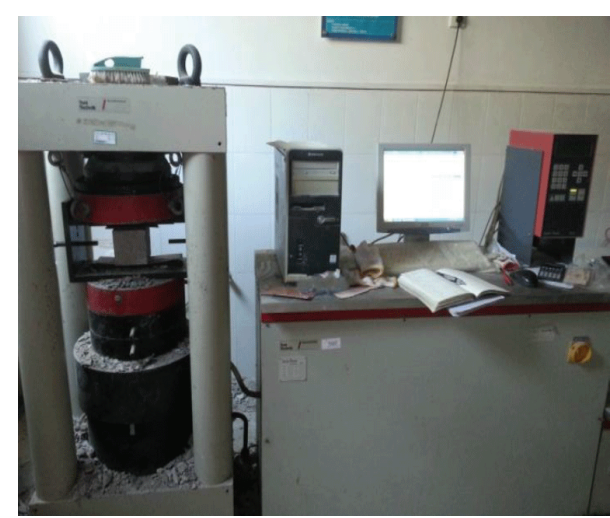

(a) Loading machine

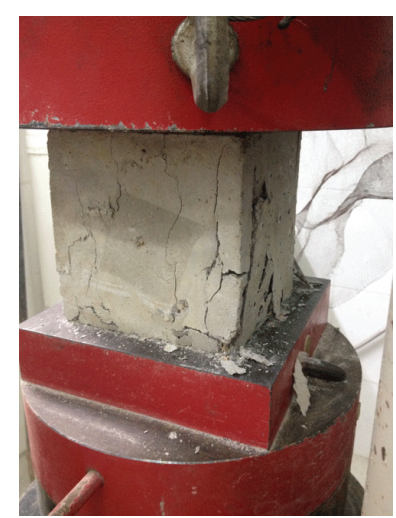

(b) Failure sample

FIgURE 2: Axial compression test setup of the corroded samples.

function was designed to help the machine automatically record the cycling state in the case of an unexpected power outage and then continue to work following the state before the power outage after the circuit is restored.

\section{Experimental Results and Discussion}

In this study, the concrete experimental samples were placed in the corrosion test chamber under the action of the dry-wet cycle. Each group (four experimental samples in each group) was removed on the 30 th, 60th, 90th, 120th, and 150th days. The compressive strength of concrete and microstructure were studied, and the corrosion depth of sulfate ions in the concrete was measured. The relevant experimental results are analyzed in detail in this section.

3.1. Variation of Concrete Strength with Corrosion Period. The variation in the average value of the concrete strength of each group in the three samples after various corrosion periods was directly measured by axial compression test under the loading rate of $0.5 \mathrm{MPa} / \mathrm{s}$ (see Figure 2). The results are shown in Figure 3 and Table 4.

Figure 3 shows that the strength of concrete after sulfate corrosion has an obvious rise period and decline area, consistent with the findings of existing studies. At the 60th day, the strength of concrete reached its peak and increased by $\sim 6.4 \%$ on the basis of its uncorroded strength. However, with the continuous increase in the amount of degradation periods, the strength of concrete decreased continually, and the compressive strength decreased by $\sim 4.4 \%, 18 \%$, and $43.1 \%$ after 90,120, and 150 days of corrosion, respectively.

At the initial stage of corrosion, the strength increased due to the generation of expansive products such as ettringite and gypsum [12-14], which made the concrete more compact. However, at the later stage of corrosion, with the continuous growth of corrosion products and sodium sulfate crystals, the crystallization pressure on the pore wall started to exist and grow and eventually exceeded the tensile stress of concrete and thus caused microdamage [30, 31]. Sodium sulfate crystals mainly formed during the drying process and can generate a high expansive stress of up to $20 \mathrm{MPa}$ to

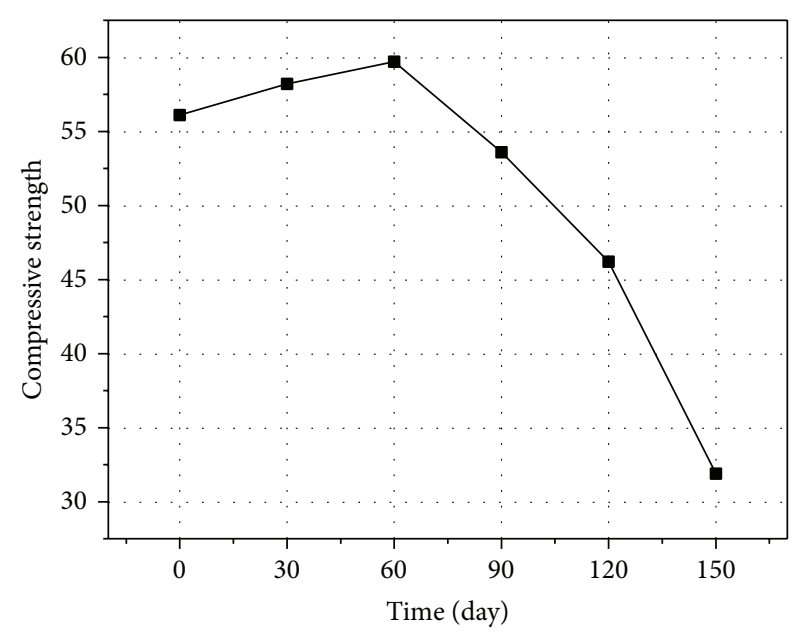

FIGURE 3: Variation in the average value of the compressive strength of corroded concrete.

concrete by filling the concrete pore structure [30]. Though some sulfate crystal dissolved in the wet cycle when the solution became nonsaturated, the existing crack is hard to recover. Therefore, the strength of concrete decreased. Moreover, studies have reported that ettringite precipitates at the interface between the cement paste and aggregate [28] and thus may reduce the bond performance between the cement pastes and aggregate when a certain amount is reached. The concrete became loose and suffered stripping, peeling, and other defects even if a relatively small pressure was applied. These internal reasons further resulted in different morphologies of concrete as shown in Figure 4. Figures 4(a), 4(b), 4(c), and 4(d) show the morphological differences of concrete after various corrosion periods, while Figures 4(e), 4(f), 4(g), and 4(h) further illustrate their corresponding compression failure morphologies. Compared to the uncorroded experimental samples before and after compression as shown in Figures 4(a) and 4(e), the sample after 60 days of corrosion exhibited improved overall strength and increased number and width of cracks in the vertical direction at failure 


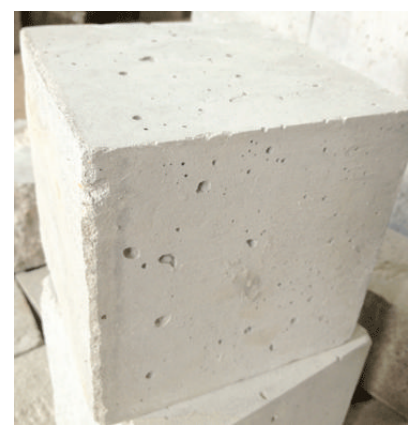

(a) 0 days- $\mathrm{C}$

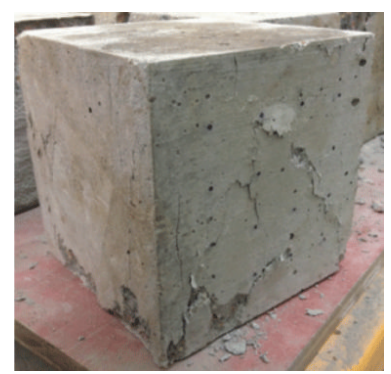

(e) 0 days-F

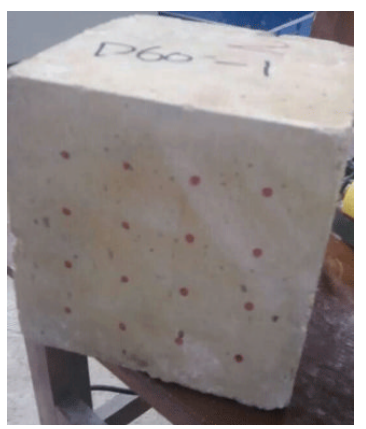

(b) 60 days- $\mathrm{C}$

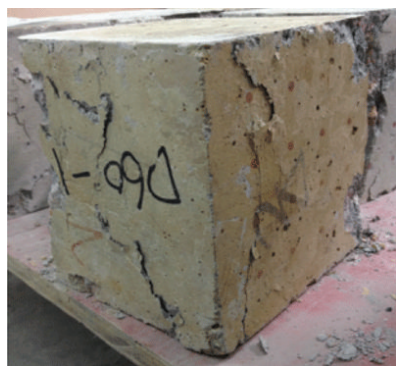

(f) 60 days-F

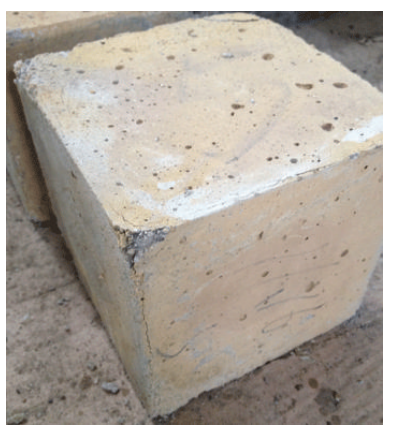

(c) 120 days- $\mathrm{C}$

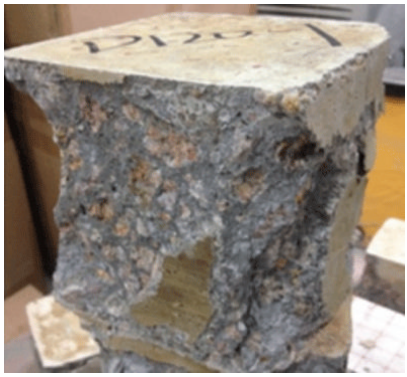

(g) 120 days- $\mathrm{F}$

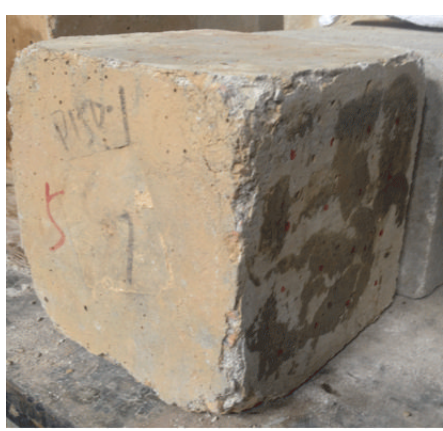

(d) 150 days- $\mathrm{C}$

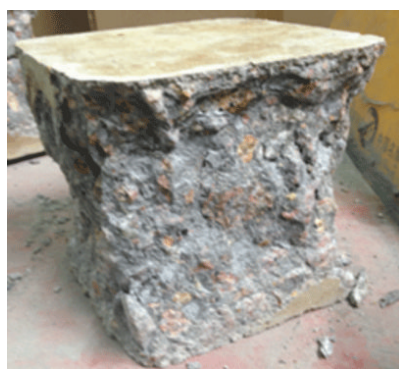

(h) 150 days-F

FIGURE 4: Corrosion morphology and compressive failure mode of concrete after various degradation periods (note that C denotes the corrosion morphology and $\mathrm{F}$ denotes the failure mode).

(see Figure 4(f)) due to the compacting action of corrosion products (see Figure 4(b)). Figures 4(g) and 4(h) show the compression failure morphologies of the concrete samples after 120 and 150 days of corrosion, respectively, indicating increased degree of corrosion, severe strength deterioration of concrete surface, and more obvious overall fragmentation were observed at failure, as the corroded concrete became more looser and cracked more heavily (see Figures 4(c) and $4(d))$.

\subsection{Microstructure Analysis of Concrete under Sulfate Cor-} rosion. The microstructural change in concrete under the dry-wet cycling action of sulfates was analyzed in this section to explain the macrostrength change of concrete. The morphologies of the surface layers ( $5 \mathrm{~mm}$ in thickness) of uncorroded and nonpressurized concrete after 60 and 150 days of corrosion were studied by scanning electron microscope (SEM). The results are shown in Figure 5. It should be noted that Figure 5 mainly shows the change of the microcracks and the morphologies of corrosion products after corrosion.

Figures 5(a) and 5(b) show the microstructures of the uncorroded concrete samples. It is observed that the internal hydration product, mainly the calcium hydroxide, which was highly distributed near the micropores and microfractures of concrete, had a complete and compact structure. In addition, a lot of fibrous and flocculent hydrated calcium silicate but no obvious corrosion products or microdamage was observed in the figures as no external sulfate ions entered into concrete. Figures 5(c) and 5(d) show the surface microstructures of the concrete samples after 60 days of corrosion. On one hand, the hydration reaction of concrete itself made the structure of the hydration product more compact and continuous; on the other hand, expansive products, that is, ettringite and gypsum, were generated due to the attack by external sulfate ions and their reactions with calcium aluminate hydrate. With the continuous precipitation of ettringite near those micropores and microfractures [28], the initial pores inside concrete were gradually filled and the internal structure of concrete became more compact. Although these expansive products would exert a certain expansive stress on concrete, they did not reach the tensile strength of concrete and cannot produce fractures. These explain the increase in the abovementioned macromechanical performance at the microstructure level. Figures 5(e), 5(f), and 5(g) show the surface microstructures of concrete after 150 days of corrosion, indicating the massive cracks and denudation of cement paste due to the dry-wet cycling action, crystal growth, and expansion. Figures $5(\mathrm{f})$ and $5(\mathrm{~g})$ further show some needle-like ettringite crystals in relatively large cracks which coexisted with the calcium silicate hydrate (C-S-H) gel and were enclosed by a large amount of gypsum. This indicates that in a highconcentration sulfate solution, the generation of gypsum plays a dominant role, consistent with the results reported previously $[8,29]$. Because of the corrosive deterioration of its internal composition, the severe cracking of microstructure, and the looseness of concrete itself, the macromechanical performance declined significantly.

3.3. Distribution of Sulfate Ions in Concrete and Development of Corrosion Depth. The cores of the concrete after various corrosion periods were sampled, sliced by layers (each layer 


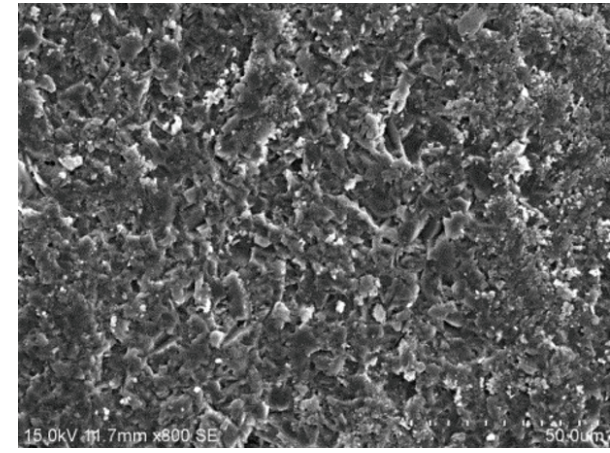

(a) Microstructure of uncorroded concrete

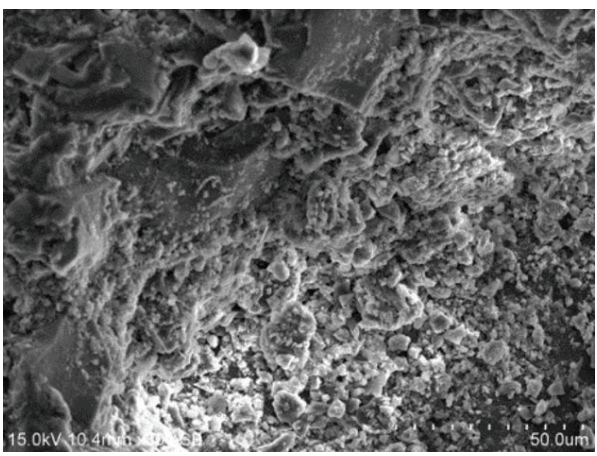

(c) Microstructure of concrete after 60 days of corrosion

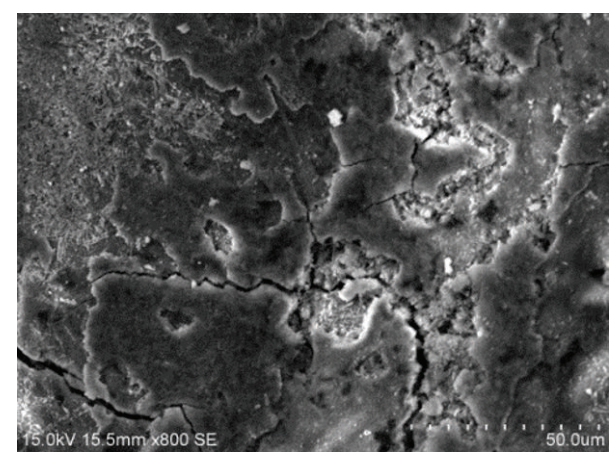

(e) Microstructure of concrete after 150 days of corrosion

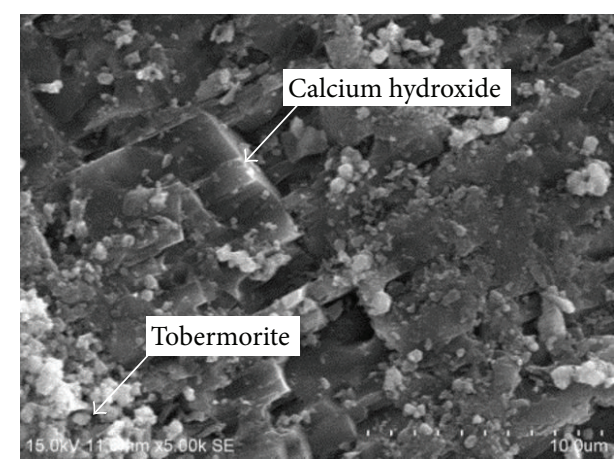

(b) Local features of the microstructure of uncorroded concrete

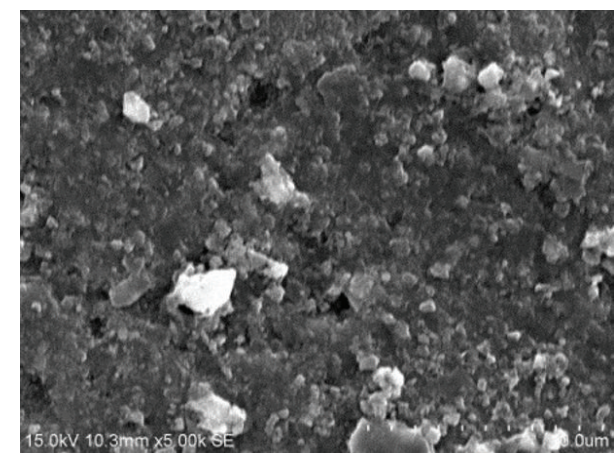

(d) Local features of the microstructure of concrete after 60 days of corrosion

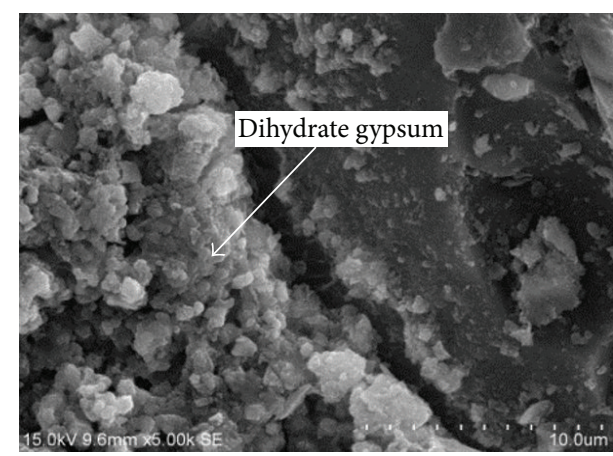

(f) Local features of the microstructure of concrete after 150 days of corrosion

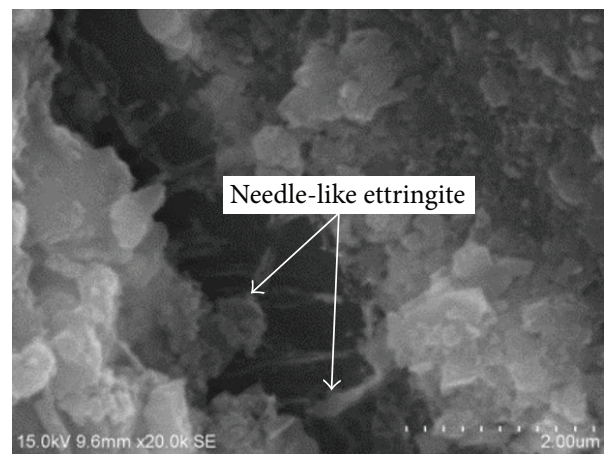

(g) Enlarged view of the internal fractures of concrete after 150 days of corrosion

Figure 5: Micromorphology of concrete. 


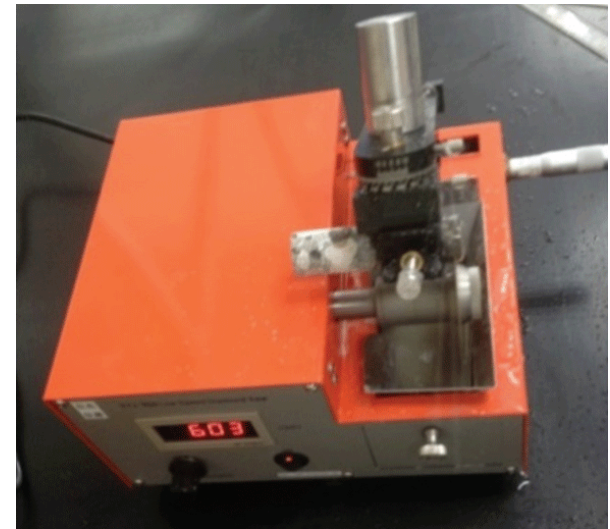

(a) Slice machine

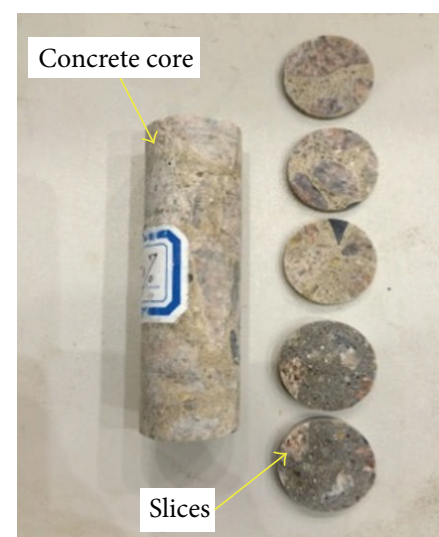

(b) Concrete core and slices

FIGURE 6: Slice machine and the samples.

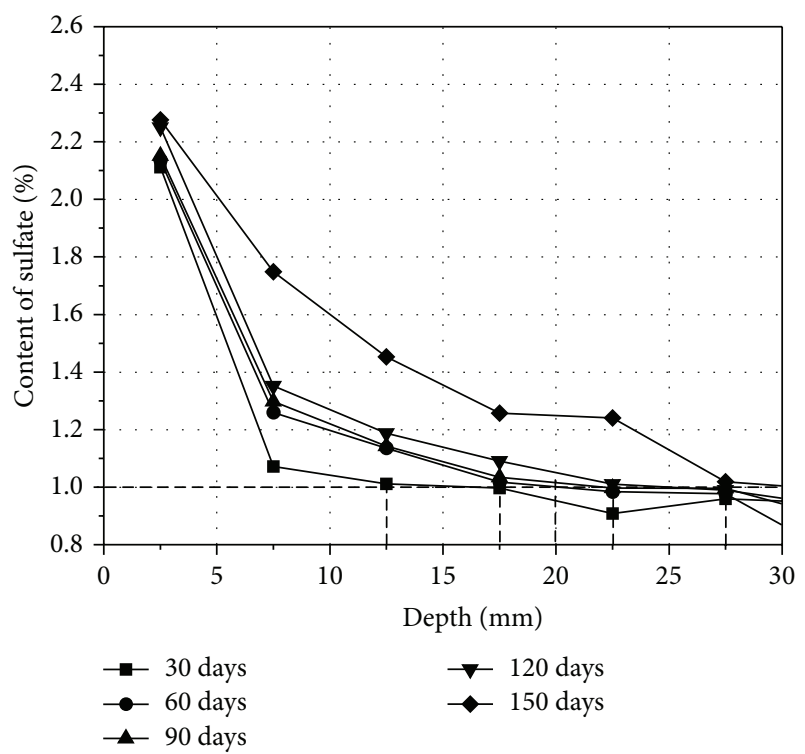

FIGURE 7: Distribution of sulfate ions in concrete.

had a minimum slicing thickness of $5 \mathrm{~mm}$ corresponding to depths of 2.5, 7.5, and $12.5 \mathrm{~mm}$ from exposure surface and gradually increased by an increment of $5 \mathrm{~mm}$ ) as shown in Figure 6, and ground into powder. The chemical analysis of the sulfate ions of concrete was performed, and the distribution of sulfate ions from the outside to the inside of concrete after various degradation periods was measured as shown in Figure 7. The main steps are shown in ASTM C1142010 [32].

Figure 7 shows the distribution of sulfate ions at various depths of concrete at the same corrosion age. It can be observed that, under the action of the dry-wet cycle, the amounts of sulfate ions on concrete surface became saturated soon with the progress of corrosion. Therefore, the concentration of sulfate ions in the first layer at each corrosion age showed no apparent gradient. The figure also indicates no obvious boundary between the corroded and uncorroded sections of the concrete. The closer to the surface, the more severe the degradation; the closer to the core, the less severe the degradation. Therefore, in this paper, the corrosion depth at which the concentration of sulfate ions in concrete can approximately reach or slightly exceed the initial concentration (the initial concentration of sulfates in concrete in this study was $\sim 1 \%$ ) is defined as the corrosion depth in Figure 7. Based on this definition, the corrosion depth at 30 days of corrosion was deduced to be $12.5 \mathrm{~mm}$ as shown in Figure 7, as the amount of sulfate ions at $12.5 \mathrm{~mm}$ reached $1.031 \%$; approximately the initial concentration was $1 \%$. With the initial concentration of $1 \%$ as the evaluation basis of the corrosion depth, in the same manner, the corrosion depths after other corrosion periods can be derived as shown in Table 4. It is easy to find that the change in the strength of corroded concrete was closely related to the development of corrosion depth by sulfates.

\section{Sulfate Diffusion Based Strength Deterioration Model of Concrete under Sulfate Corrosion}

The above analysis reveals that sulfate corrosion significantly affects the compressive strength of concrete, and a significant correlation exists between the depth of sulfate corrosion and the strength of concrete as shown in Table 4. Therefore, the corroded concrete strength can be derived if the sulfate corrosion depth is known and moreover such a correlation is explicit. This section aims to develop a strength deterioration model. According to the strength variation, as shown in Figure 7, the corroded concrete can be divided into three layers from the exposure surface to the core, that is, corroded layer, compacted layer, and uncorroded layer, as shown in Figure 8(a). In fact, the compacted layer is the transitional layer of the corroded layer, and it has a so small relative thickness that it can almost be neglected. Consequently, the compacted layer can be simply classified into the corroded layer and the corroded concrete section is divided into corroded and uncorroded layers as shown in Figures 8(b) and 


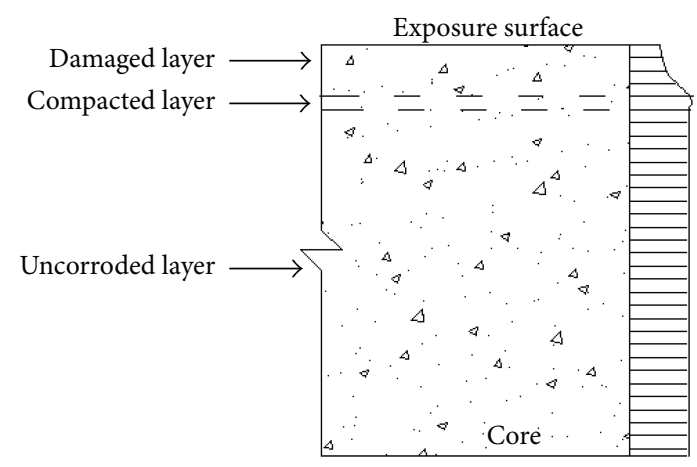

(a) Actual strength distribution of corroded concrete

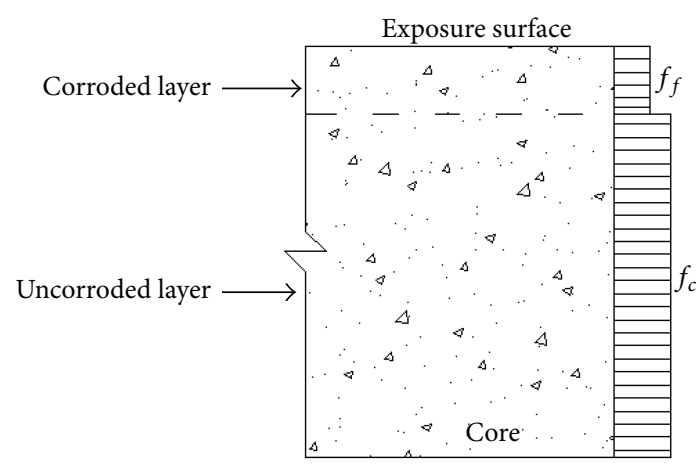

(b) Simplified strength distribution of corroded concrete

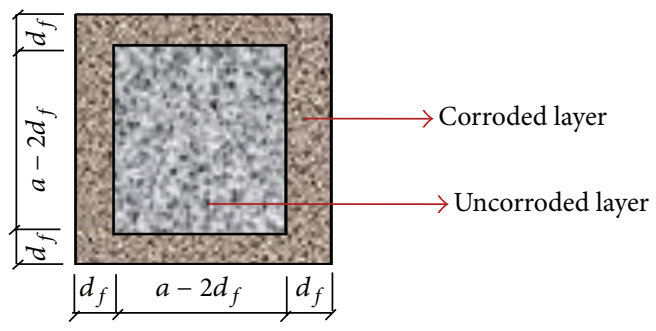

(c) Schematic diagram of the corroded concrete section

FIGURE 8: Simplified distribution of the strength of sulfate-corroded concrete.

8(c), and thus two strengths, that is, the average compressive strength of the entire corroded concrete and the strength of only corroded concrete layer (see Figures $8(\mathrm{~b})$ and $8(\mathrm{c})$ ), were investigated in this study. Herein, the average compressive strength of the entire corroded concrete was defined as the overall average strength of corroded and uncorroded layers and was called an average strength for short in the following studies.

4.1. Deterioration Model of the Average Strength of Corroded Concrete. As aforementioned, the depth of sulfate corrosion can be used as an effective index to evaluate the mechanical performance deterioration of the concrete after corrosion. For convenience and simplicity, the concept of relative corrosion depth $\delta$ was first introduced in this section:

$$
\delta=\frac{d_{f}}{D / 2} \times 100 \%,
$$

where $d_{f}$ is the corrosion depth or the thickness of corroded concrete layer and $D$ is the dimension of the concrete sample in the depth direction of sulfate corrosion; for example, in this study, $D$ is the side length as the sample has a square section.

Moreover, the damage degree of the average strength of corroded concrete can be quantitatively characterized by the corrosion resistance coefficient $k$ as follows:

$$
k=\frac{f_{c}^{\prime}}{f_{c}},
$$

where $f_{c}$ is the measured initial compressive strength of concrete after 28 days of standard curing and $f_{c}^{\prime}$ is the measured average strength of concrete after corrosion.
Therefore, the corrosion resistance coefficient $k$ of corroded concrete and the relative corrosion depth $\delta$ were calculated and given in Table 5 .

Based on an in-depth analysis of the data shown in Table 5 where the corrosion resistance coefficient $k$ of corroded concrete first increases with the relative corrosion depth $\delta$ and then reduces sharply, a parabola-like function with an extreme point is developed to reveal the relationship between the corrosion resistance coefficient $k$ of corroded concrete and the relative corrosion depth $\delta$ :

$$
k=\varphi e^{-\left(\delta-\delta_{c}\right)^{2} / \beta}
$$

where $\varphi$ is the maximum corrosion resistance coefficient that has a value of slightly greater than 1, indicating the contribution made by the filling of corrosion products in the improvement of the compactness and strength of concrete; $\delta_{c}$ is the relative corrosion depth corresponding to the maximum value of the corrosion resistance coefficient; and $\beta$ is a parameter that characterizes the strength decay rate of concrete.

From the boundary conditions of $k=1$ when $\delta=0$, it is easy to derive that

$$
\beta=\frac{\delta_{c}^{2}}{\ln \varphi} .
$$

Substituting (4) into (3), (3) is then rederived in a more simplified form as given by

$$
k=\varphi e^{-\ln \varphi \cdot\left(\delta / \delta_{c}-1\right)^{2}}=\varphi^{1-\left(\delta / \delta_{c}-1\right)^{2}} .
$$

The two parameters $\varphi$ and $\delta_{c}$ in (5) can be derived by the numerical approximation of experimental data using (5). 
TABLE 5: Corrosion resistance coefficient and relative corrosion depth.

\begin{tabular}{lccc}
\hline Corrosion time (day) & Corrosion depth $(\mathrm{mm})$ & Relative corrosion depth $\delta(\%)$ & Corrosion resistance coefficient $k$ \\
\hline 0 & 0 & 0 & 1 \\
30 & 12.5 & 16.7 & 1.04 \\
60 & 17.5 & 23.3 & 1.06 \\
90 & 20 & 26.7 & 0.96 \\
120 & 22.5 & 30 & 0.82 \\
150 & 27.5 & 36.7 & 0.57 \\
\hline
\end{tabular}

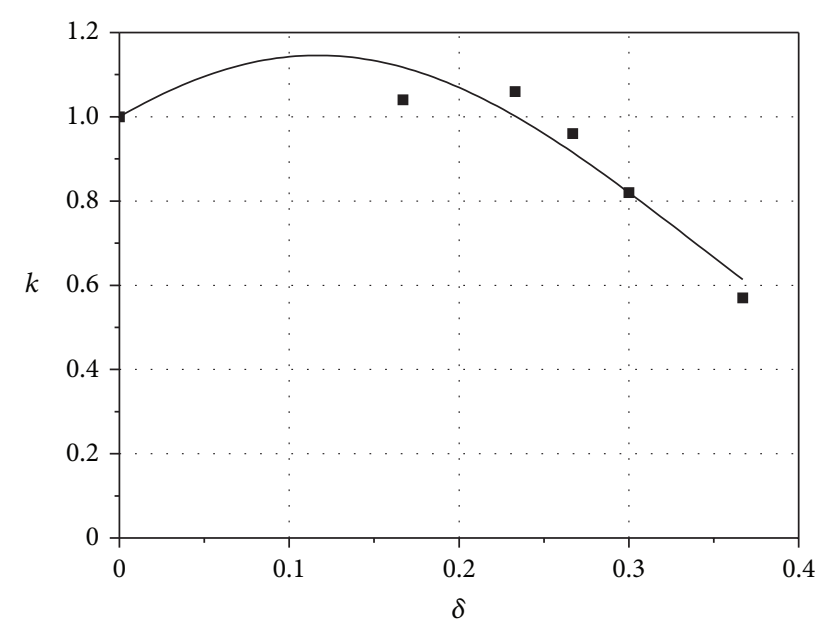

FIGURE 9: Fitting curve of corrosion resistance coefficient.

The fitting curve is plotted in Figure 9 with a correlation coefficient $R^{2}$ of 0.92 , and the model parameters of $\varphi=1.15$ and $\delta_{c}=11.7 \%$ are evaluated, indicating the high correctness of using (5) to predict the corrosion resistance coefficient.

Therefore, the average strength is finally derived by

$$
f_{c}^{\prime}=\varphi^{1-\left(\delta / \delta_{c}-1\right)^{2}} f_{c}
$$

To further demonstrate the validity and rationality of the proposed average strength model, that is, (6), more existing experimental data were also collected.

In the literature [26], a dry-wet cycling corrosion test (soaked for three days and then dried for two days) was conducted on the concrete with a strength grade of $\mathrm{C} 25$. The concrete samples were placed in a sodium sulfate solution with a concentration of $15 \%$, and the relationship between the average strength of corroded concrete and the corresponding corrosion depth was measured and shown in Table 6.

In the literature [27], the concrete with a strength grade of C25 which was mixed with $20 \%$ fly ash was placed in a sodium sulfate solution (20\%) for the full-soaking corrosion test. The relationship between the average strength of corroded concrete and the corresponding corrosion depth was obtained as shown in Table 7.

It should be noted that the sulfate corrosion depths in the literature [26] were obtained by the ultrasonic testing method, while those collected in the literature [27] were measured by both the ultrasonic testing method and the chemical analysis which is the same as that adopted in
TABLE 6: Relative corrosion depth and the corresponding average strength of corroded concrete reported in literature [26].

\begin{tabular}{lccccccc}
\hline $\begin{array}{l}\text { Corrosion time } \\
\text { (day) }\end{array}$ & 0 & 5 & 10 & 15 & 20 & 25 & 30 \\
\hline $\begin{array}{l}\text { Relative } \\
\begin{array}{l}\text { corrosion depth } \\
(\%)\end{array}\end{array}$ & 0 & 4.3 & 8.9 & 11.4 & 16.4 & 21.2 & 29.3 \\
$\begin{array}{l}\text { Average } \\
\text { strength (MPa) }\end{array}$ & 27.2 & 30.6 & 32 & 35.1 & 28.5 & 22.5 & 14.5 \\
\hline
\end{tabular}

TABLE 7: Relative corrosion depth and the corresponding average strength of corroded concrete reported in the literature [27].

\begin{tabular}{lccccc}
\hline Corrosion time (day) & 0 & 100 & 120 & 140 & 160 \\
\hline Relative corrosion depth (\%) & 0 & 15.4 & 22.2 & 27.4 & 31.8 \\
Average strength (MPa) & 24.29 & 26.88 & 24.17 & 20.91 & 17.56 \\
\hline
\end{tabular}

TABLE 8: Values of the parameters of the model under various conditions.

\begin{tabular}{lcccc}
\hline Reference & Strength grade & Fly ash & $\varphi$ & $\delta_{c}$ \\
\hline In this study & C50 & 0 & 1.15 & $11.7 \%$ \\
{$[28]$} & C25 & 0 & 1.21 & $9.2 \%$ \\
{$[29]$} & C25 & $20 \%$ & 1.13 & $11.0 \%$ \\
\hline
\end{tabular}

this paper. As concluded in the lateral literature [27] that both these two methods can lead to similar results, the data provided in Tables 6 and 7 were thus used for the further verification of the average strength model. The fitting curves using (5) are drawn in Figure 10 together with the corresponding test data, and model parameters $\varphi$ and $\delta_{c}$ are evaluated and summarized in Table 8 . Figure 10 shows that (5) has extremely high applicability and accuracy in predicting the average strength variation of concrete after sulfate corrosion. Table 8 further indicates that mixing fly ash or improving strength of concrete has little effect on the resistance of concrete to sulfate corrosion as the calculated model parameters change only very slightly.

\subsection{Strength Deterioration Model of Corroded Concrete Layer.} As discussed above, the damaged concrete section can be classified into corroded and uncorroded layers as shown in Figure $8(\mathrm{c})$. The strength deterioration of corroded layer may reduce the reinforcement-concrete bond performance. It is therefore of great significance to further study the strength deterioration of the corroded concrete layer in this section. 


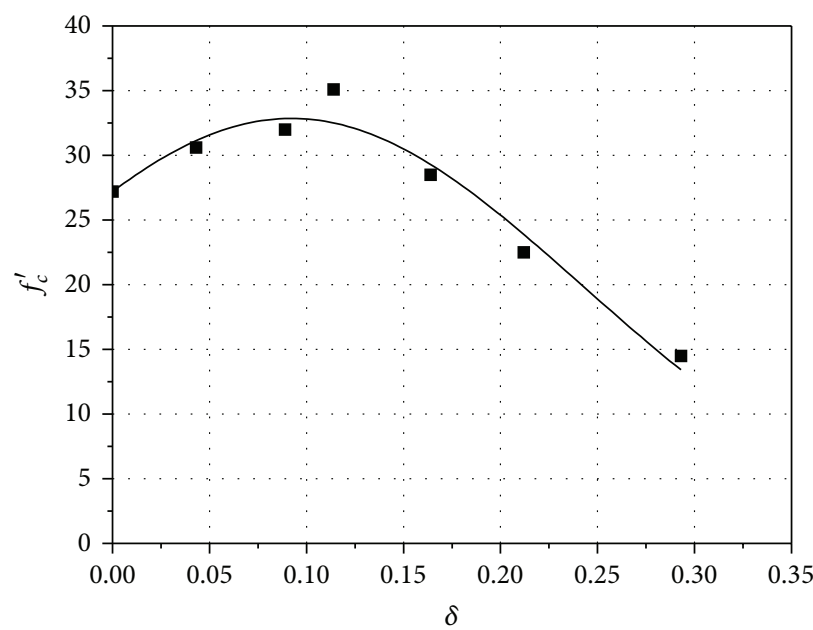

(a) Verification using the data reported in the literature [26]

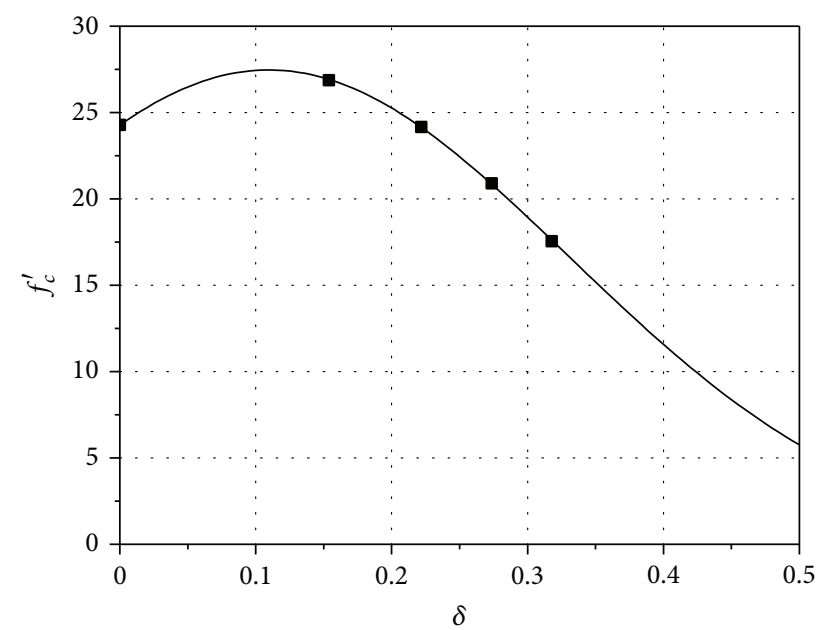

(b) Verification using the data reported in the literature [27]

FIGURE 10: Verification of the average strength deterioration model by the existing experimental data.

From the equilibrium of the corroded concrete section, as shown in Figures $8(\mathrm{~b})$ and $8(\mathrm{c})$, the following equation can be obtained:

$$
f_{c}^{\prime} A=f_{c} A_{c}+f_{f} A_{f}
$$

where $A_{c}, A_{f}$, and $A$ are the sectional areas of the uncorroded and corroded concrete layers and the total area of the entire concrete section, respectively; $f_{c}, f_{f}$, and $f_{c}^{\prime}$ represent the strengths of uncorroded and corroded concrete layers and the average strength of the entire concrete section, respectively. Herein, the sectional area of corroded concrete is related to the corroded layer thickness, which, based on the above assumptions, is exactly the depth of sulfate corrosion.

It is self-evident that the strength $f_{f}$ of a corroded concrete layer cannot be directly measured by tests; however, it can be solved from (7) once the thickness of corroded concrete layer $d_{f}$ and the average strength $f_{c}^{\prime}$ are both determined. The results of the solution are given in Table 9.

Table 9 shows that the derived strength of corroded concrete layer increased first and then decreased. Similarly, the corrosion resistance coefficient $k^{\prime}=f_{f} / f_{c}$ of the strength of corroded concrete layer is introduced and evaluated in Table 9 as well, from which the correlation between the corrosion resistance coefficient of the strength of corroded concrete layer and the corrosion depth can be obtained as shown in Figure 11.

Figure 11 shows that the variation of the corrosion resistance coefficient of the strength of a corroded concrete layer with corrosion depth has a similar trend with that of the average strength of concrete, and hence the function form of (5) can also be applied to describe such development trend; thus

$$
k^{\prime}=\varphi_{f}^{1-\left(\delta / \delta_{c}^{\prime}-1\right)^{2}} .
$$

Therefore, the strength of corroded concrete layer can be derived as follows:

$$
f_{f}=\varphi_{f}^{1-\left(\delta / \delta_{c}^{\prime}-1\right)^{2}} f_{c}
$$

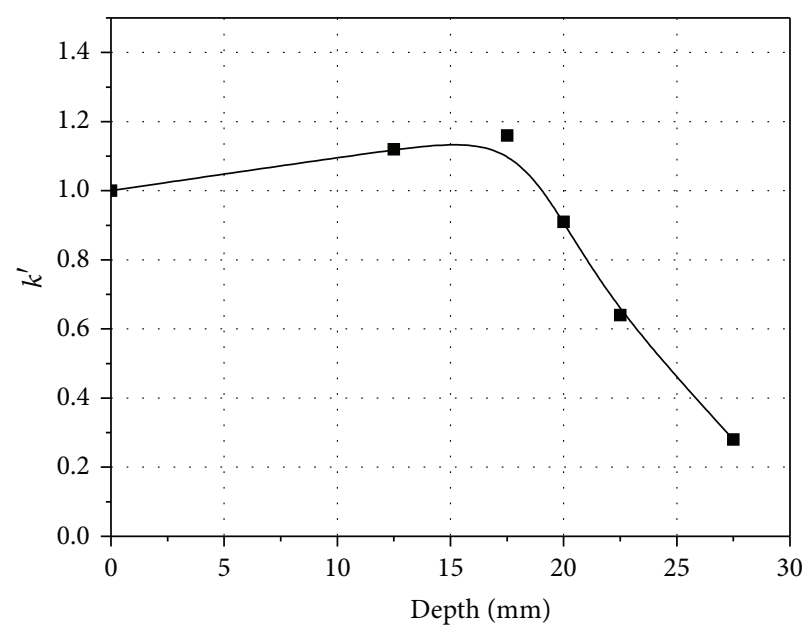

FIGURE 11: Correlation between the corrosion resistance coefficient of the strength of corroded concrete layer and the corrosion depth.

where $\varphi_{f}$ is defined as the maximum corrosion resistance coefficient of corroded concrete layer which has a value of greater than 1, also indicating the contribution made by the filling of corrosion products in the improvement of the compactness and strength of concrete; $\delta_{c}^{\prime}$ is the relative corrosion depth or the relative thickness of corroded layer corresponding to the maximum value of the corrosion resistance coefficient of corroded concrete layer.

It is self-evident that the strength of corroded layer and the average strength simultaneously reached the maximum value; that is, $\delta_{c}^{\prime}=\delta_{c}$. Given that, the value of $\varphi_{f}$ can be derived as follows.

From the definitions of the corrosion resistance coefficient, the following relations exist:

$$
\begin{aligned}
& f_{c}^{\prime}=\varphi f_{c}, \\
& f_{f}=\varphi_{f} f_{c} .
\end{aligned}
$$


TABLE 9: Calculated results of the compressive strength of corroded concrete layer.

\begin{tabular}{lcccccccc}
\hline Corrosion time/day & Corrosion depth/mm & $A / \mathrm{mm}$ & $A_{c} / \mathrm{mm}$ & $A_{f} / \mathrm{mm}$ & $f_{c}^{\prime} / \mathrm{MPa}$ & $f_{c} / \mathrm{MPa}$ & $f_{f} / \mathrm{MPa}$ & $k^{\prime}$ \\
\hline 0 & 0 & 22500 & 22500 & 0 & - & 56.1 & - & - \\
30 & 12.5 & 22500 & 15625 & 6875 & 58.2 & 56.1 & 63.0 & 1.12 \\
60 & 17.5 & 22500 & 13225 & 9275 & 59.7 & 56.1 & 64.8 & 1.16 \\
90 & 20 & 22500 & 12100 & 10400 & 53.6 & 56.1 & 50.7 & 0.91 \\
120 & 22.5 & 22500 & 11025 & 11475 & 45.8 & 56.1 & 35.9 & 0.64 \\
150 & 27.5 & 22500 & 9025 & 13475 & 31.9 & 56.1 & 15.7 & 0.28 \\
\hline
\end{tabular}

Substituting (11) and (12) into (9), one can obtain

$$
\varphi A=A_{C}+\varphi_{f} A_{f}
$$

Based on Figure 8(c), taking a cubic concrete sample with a side length of $a$ as the object of study, the areas $A_{c}, A_{f}$, and $A$ are related as follows:

$$
\begin{aligned}
A & =a^{2} ; \\
A_{C} & =\left(a-2 d_{f}\right)^{2} ; \\
A_{f} & =a^{2}-\left(a-2 d_{f}\right)^{2} .
\end{aligned}
$$

Substituting (1) and (12) into (11), the relationship between $\varphi_{f}$ and $\varphi$ is finally derived as follows:

$$
\varphi_{f}=\frac{(\varphi-1)\left(1-\delta_{c}\right)^{2}}{1-\left(1-\delta_{c}\right)^{2}}+\varphi .
$$

Note that if the shape of sample has been changed to prism or cylinder, (13) still works.

Consequently, the strength of corroded concrete layer can be calculated using (9) and (13). The accuracy and rationality of (9) in predicting the strength of corroded concrete layer are further verified using the aforementioned experimental data hereafter.

As far as the test designed in this study was concerned, given that $\delta_{c}^{\prime}=\delta_{c}=11.7 \%$ and $d_{f}=8.75 \mathrm{~mm}, \varphi_{f}=1.68$ can be solved using (13). The predicted curve of the strength of corroded concrete layer can be plotted in Figure 12 by substituting the above parameters into (9). The absolute value of the average error of prediction was calculated to be $10.1 \%$.

The data reported in the literatures $[26,27]$ were used in the same manner to verify the model. The above relative corrosion depths corresponding to the maximum value of the corrosion resistance coefficient $k$ as given in Table 8 were first substituted into (13), and $\varphi_{f}$ values were then calculated to be 2.2 and 1.625, respectively. These parameters were further substituted into (9), and the predicted curves of the strength of corroded concrete layer of these two studies were evaluated as shown in Figure 13, respectively. The average prediction errors were $8.9 \%$ and $12.5 \%$, also indicating the relatively high accuracy of (9).

From the verification of abovementioned strength model of corroded concrete, it is found that although the strengthening effect of sulfate corrosion on the strength of corroded concrete layer due to the improvement of the compactness

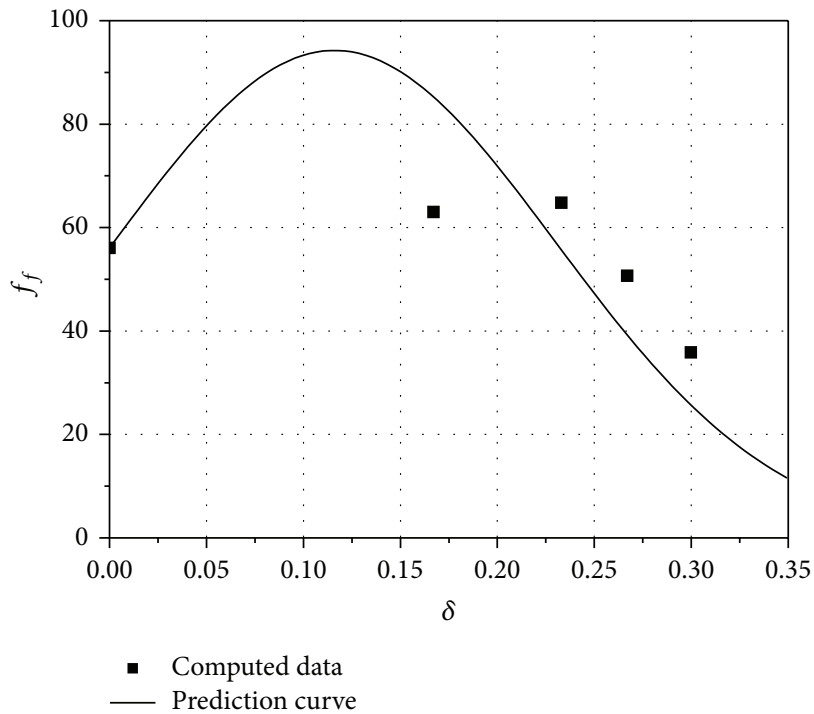

FIGURE 12: Strength of corroded layer and predicted curve.

of concrete by the filling of corrosion products varied significantly $\left(\varphi_{f}=1.68,2.2\right.$, and 1.63$)$ with the sulfate corrosion environment and the strength of concrete, the strengthening effect of sulfate corrosion on the average strength of corroded concrete was almost the same $(\varphi=1.15,1.21$, and 1.13). Therefore, the differences in the sulfate corrosion environment and the strength of concrete were not sensitive to the improvement of the average strength of corroded concrete. Thus, in actual applications, the parameters of the average strength deterioration model of corroded concrete can be selected as per the average value, that is, $\varphi=1.16$ and $\delta_{c}=10.6 \%$, regardless of the type of sulfate corrosion environments and the strength grade of concrete.

\section{Conclusions}

A systematic experimental study and mechanism analysis on the strength degradation of concrete under sulfate corrosion were performed in this study, and the relationship between the strength deterioration of concrete and the sulfate corrosion depth was established. The conclusions can be drawn as follows.

(1) The strength degradation of concrete under the dry-wet cycling action of sulfate solution was studied; the results indicate that the strength of concrete after sulfate corrosion showed an obvious rise period and decline area. 


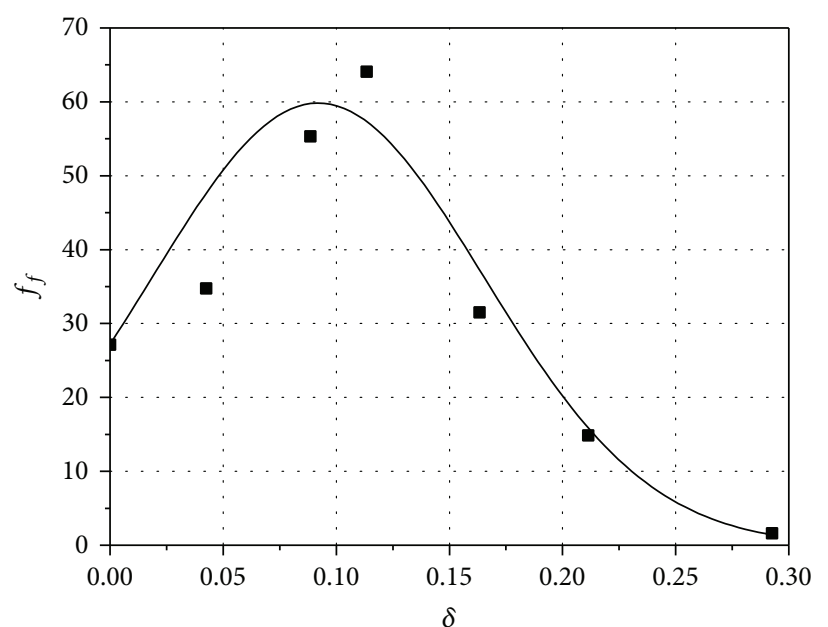

- Computed data

- Prediction curve

(a) Verification using the test data reported in the literature [26]

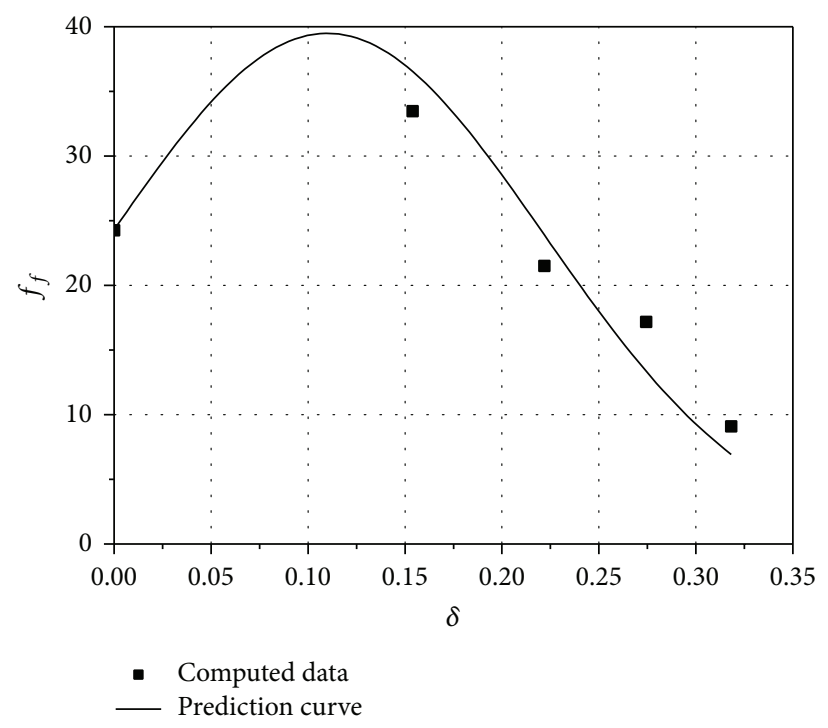

(b) Verification using the test data reported in the literature [27]

FIGURE 13: Verification of (9) proposed in this study by the existing experimental data.

The strength of concrete reached its peak at the 60th day of corrosion and increased by $\sim 6.4 \%$ on the basis of its initial strength. However, with the increase in degradation period, the strength of concrete decreased continuously. The compressive strength decreased by $\sim 4.4 \%, 18 \%$, and $43.1 \%$ after 90,120 , and 150 days of corrosion, respectively.

(2) The permeation depth of sulfate ions in concrete under the dry-wet cycling action of sulfate solution was also studied. The results indicate a certain correlation between the concrete corrosion depth by sulfates and the strength of concrete. By deriving the strength of concrete from the corrosion depth, an average strength deterioration model of concrete was developed. The relatively high accuracy and applicability of the model were verified by a large amount of experimental data.

(3) The concrete section corroded by sulfates was classified into corroded and uncorroded layers. By deriving the strength of concrete from the corrosion depth, a strength deterioration model of corroded concrete layer was developed, and the relatively high accuracy and applicability of the model were also verified by a large amount of experimental data.

\section{Conflict of Interests}

The authors declare that there is no conflict of interests regarding the publication of this paper.

\section{Acknowledgments}

The work described in this paper was financially supported by the Ministry of Science and Technology for the 973Project (no. 2011CB013604) and the National Natural Science Foundation of China (Grants nos. 51378314, 51108272, and 51178271) to which the authors are grateful.

\section{References}

[1] J. R. Clifton and J. M. Pommersheim, Sulfate Attack of Cementitious Materials:Volumetric Relations and Expansions, Building and Fire Research Laboratory, National Institute of Standards and Technology, Gaithersburg, Md, USA, 1994.

[2] C. Sun, J. Chen, J. Zhu, M. Zhang, and J. Ye, "A new diffusion model of sulfate ions in concrete," Construction and Building Materials, vol. 39, pp. 39-45, 2013.

[3] A. Bonakdar, B. Mobasher, and N. Chawla, "Diffusivity and micro-hardness of blended cement materials exposed to external sulfate attack," Cement and Concrete Composites, vol. 34, no. 1, pp. 76-85, 2012.

[4] A. E. Idiart, C. M. López, and I. Carol, "Chemo-mechanical analysis of concrete cracking and degradation due to external sulfate attack: a meso-scale model," Cement and Concrete Composites, vol. 33, no. 3, pp. 411-423, 2011.

[5] S. Lorente, M.-P. Yssorche-Cubaynes, and J. Auger, "Sulfate transfer through concrete: migration and diffusion results," Cement and Concrete Composites, vol. 33, no. 7, pp. 735-741, 2011.

[6] J. Condor, K. Asghari, and D. Unatrakarn, "Experimental results of diffusion coefficient of sulfate ions in cement type 10 and class G," Energy Procedia, vol. 4, pp. 5267-5274, 2011.

[7] E. Rozière, A. Loukili, R. Hachem, and F. Grondin, "Durability of concrete exposed to leaching and external sulphate attacks," Cement and Concrete Research, vol. 39, no. 12, pp. 1188-1198, 2009.

[8] M. Santhanam, M. D. Cohen, and J. Olek, "Modeling the effects of solution temperature and concentration during sulfate attack on cement mortars," Cement and Concrete Research, vol. 32, no. 4, pp. 585-592, 2002.

[9] J. M. Pommersheim and J. R. Clifton, "Expansion of cementitious materials exposed to sulfate solutions, scientific basis for nuclear waste management," Materials Research Society, vol. 333, pp. 363-368, 1994. 
[10] R. Tixier and B. Mobasher, "Modeling of damage in cementbased materials subjected to external sulfate attack. I. Formulation," Journal of Materials in Civil Engineering, vol. 15, no. 4, pp. 305-313, 2003.

[11] R. Tixier and B. Mobasher, "Modeling of damage in cementbased materials subjected to external sulfate attack II: comparison with experiments sulfate attack mechanisms," Journal of Materials in Civil Engineering, vol. 15, no. 4, pp. 314-322, 2003.

[12] N. N. Naik, A. C. Jupe, S. R. Stock, A. P. Wilkinson, P. L. Lee, and K. E. Kurtis, "Sulfate attack monitored by microCT and EDXRD: influence of cement type, water-to-cement ratio, and aggregate," Cement and Concrete Research, vol.36, no. 1, pp.144$159,2006$.

[13] S. U. Al-Dulaijan, "Sulfate resistance of plain and blended cements exposed to magnesium sulfate solutions," Construction and Building Materials, vol. 21, no. 8, pp. 1792-1802, 2007.

[14] M. H. Zhang, J. K. Chen, Y. F. Lv, D. J. Wang, and J. Ye, "Study on the expansion of concrete under attack of sulfate and sulfatechloride ions," Construction and Building Materials, vol. 39, pp. 26-32, 2013.

[15] Y.-S. Parka, J.-K. Suhb, J.-H. Leec, and Y.-S. Shinc, "Strength deterioration of high strength concrete in sulfate environment," Cement and Concrete Research, vol. 29, no. 9, pp. 1397-1402, 1999.

[16] E. Güneyisi, M. Gesoğlu, and K. Mermerdaş, "Strength deterioration of plain and metakaolin concretes in aggressive sulfate environments," Journal of Materials in Civil Engineering, vol. 22, no. 4, pp. 403-407, 2010.

[17] M. Sumer, "Compressive strength and sulfate resistance properties of concretes containing Class F and Class C fly ashes," Construction and Building Materials, vol. 34, pp. 531-536, 2012.

[18] Q. K. Nie, C. J. Zhou, X. Shu, Q. He, and B. S. Huang, "Chemical, mechanical, and durability properties of concrete with local mineral admixtures under sulfate environment in Northwest China," Materials, vol. 7, no. 5, pp. 3772-3785, 2014.

[19] K. Sotiriadis, E. Nikolopoulou, and S. Tsivilis, "Sulfate resistance of limestone cement concrete exposed to combined chloride and sulfate environment at low temperature," Cement and Concrete Composites, vol. 34, no. 8, pp. 903-910, 2012.

[20] M. L. Nehdi, A. R. Suleiman, and A. M. Soliman, "Investigation of concrete exposed to dual sulfate attack," Cement and Concrete Research, vol. 64, pp. 42-53, 2014.

[21] Y. F. Fan, Z. G. Huang, L. G. Guo, J. M. Li, and G. S. Zheng, "Concrete sulfate corrosion mechanics performance study," Journal of Zhengzhou University of Technology, vol. 20, no. 1, pp. 91-93, 1999 (Chinese).

[22] J. S. Zhang, Y. H. Zhang, L. P. Feng, Q. Y. Dong, and Z. C. Wang, "Corrosion resistance coefficient for concrete compressive strength under sulfate environment," Journal of Building Materials, vol. 3, no. 17, pp. 369-377, 2014 (Chinese).

[23] M. Shazali, M. H. Baluch, and A. H. Al-Gadhib, "Predicting residual strength in unsaturated concrete exposed to sulfate attack," Journal of Materials in Civil Engineering, vol. 18, no. 3, pp. 343-354, 2006.

[24] U. Schneider and S.-W. Chen, "Modeling and empirical formulas for chemical corrosion and stress corrosion of cementitious materials," Materials and Structures, vol. 31, no. 10, pp. 662-668, 1998.

[25] H. Song and J. K. Chen, "Effect of damage evolution on poisson's ratio of concrete under sulfate attack," Acta Mechanica Solida Sinica, vol. 24, no. 3, pp. 209-215, 2011.
[26] F. Shi and J. H. Wang, "Performance degradation of cube attacked by sulfate," Concrete, vol. 3, pp. 52-53, 2013 (Chinese).

[27] J. M. Du, Y. N. Liang, and F. J. Zhang, Mechanism and Performance Degradation of Underground Structure Attacked by Sulfate, China Railway Publishing House, Beijing, China, 2011 (Chinese).

[28] N. Thaulow and U. H. Jakobsen, "The diagnosis of chemical deterioration of concrete by optical microscopy," in Mechanism of Chemical Degradation of Cement-Based Systems, Y. Scrivener, Ed., pp. 3-13, E\&FN Spon, London, UK, 1997.

[29] I. Biczok, Concrete Corrosion and Concrete Protection, Chemical Publishing, New York, NY, USA, 1967.

[30] R. J. Flatt, "Salt damage in porous materials: how high supersaturations are generated," Journal of Crystal Growth, vol. 242, no. 3-4, pp. 435-454, 2002.

[31] N. Tsui, R. J. Flatt, and G. W. Scherer, "Crystallization damage by sodium sulfate," Journal of Cultural Heritage, vol. 4, no. 2, pp. 109-115, 2003.

[32] American Society for Testing and Materials, ASTM C114-2010. Standard Test Methods for Chemical Analysis of Hydraulic Cement, American Society for Testing and Materials, West Conshohocken, Pa, USA, 2010. 

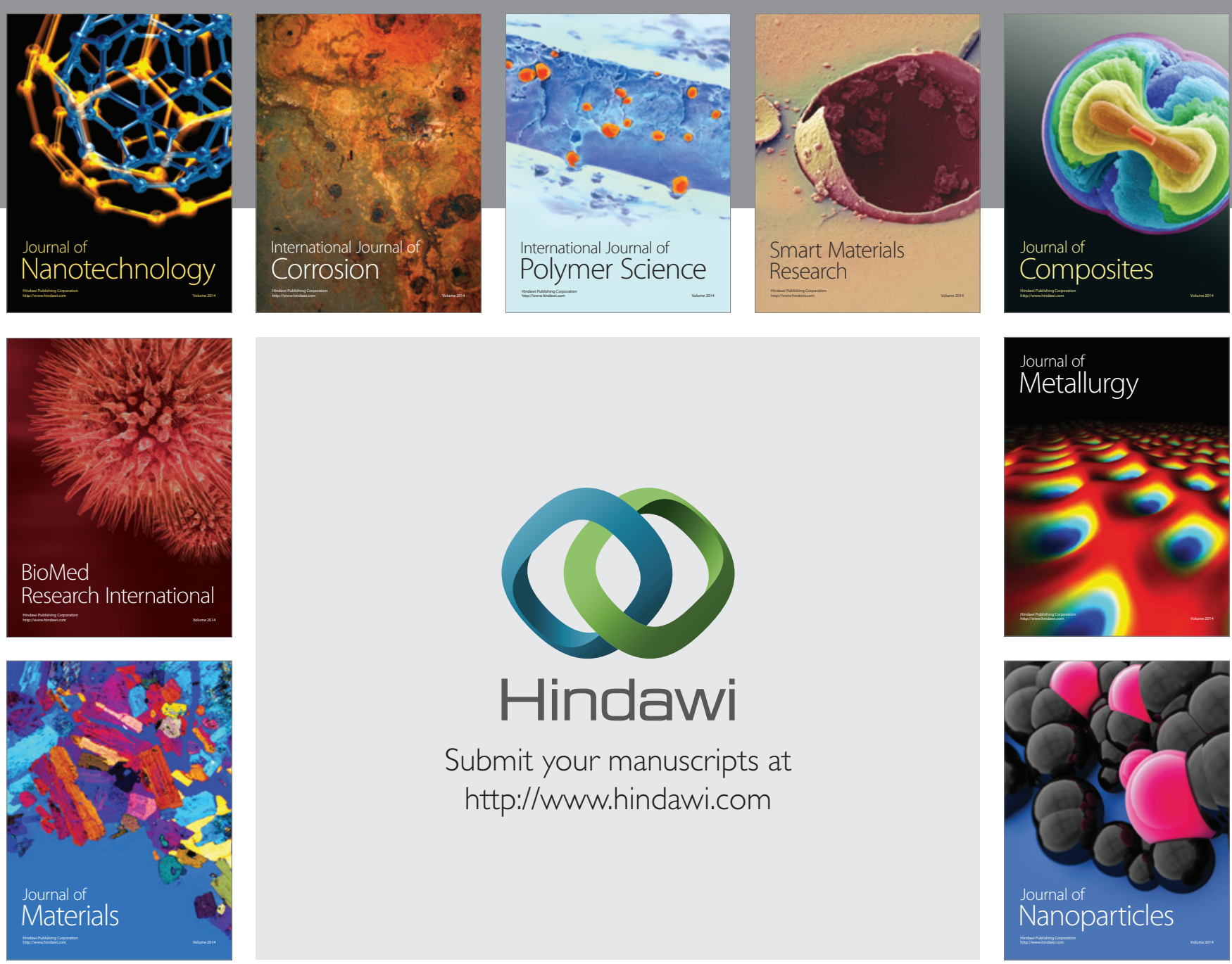

Submit your manuscripts at http://www.hindawi.com
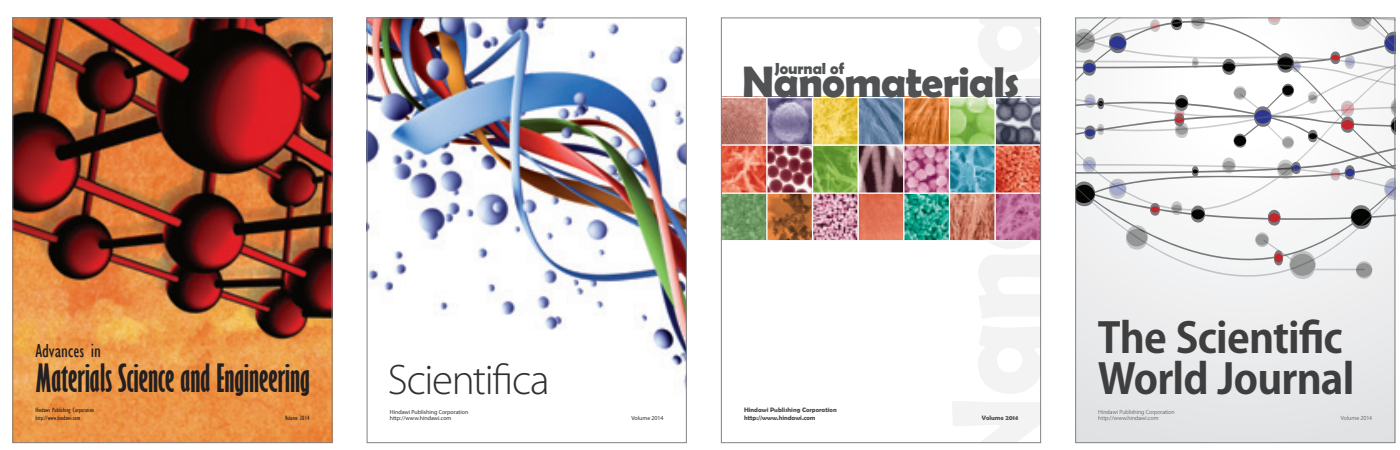

\section{The Scientific World Journal}
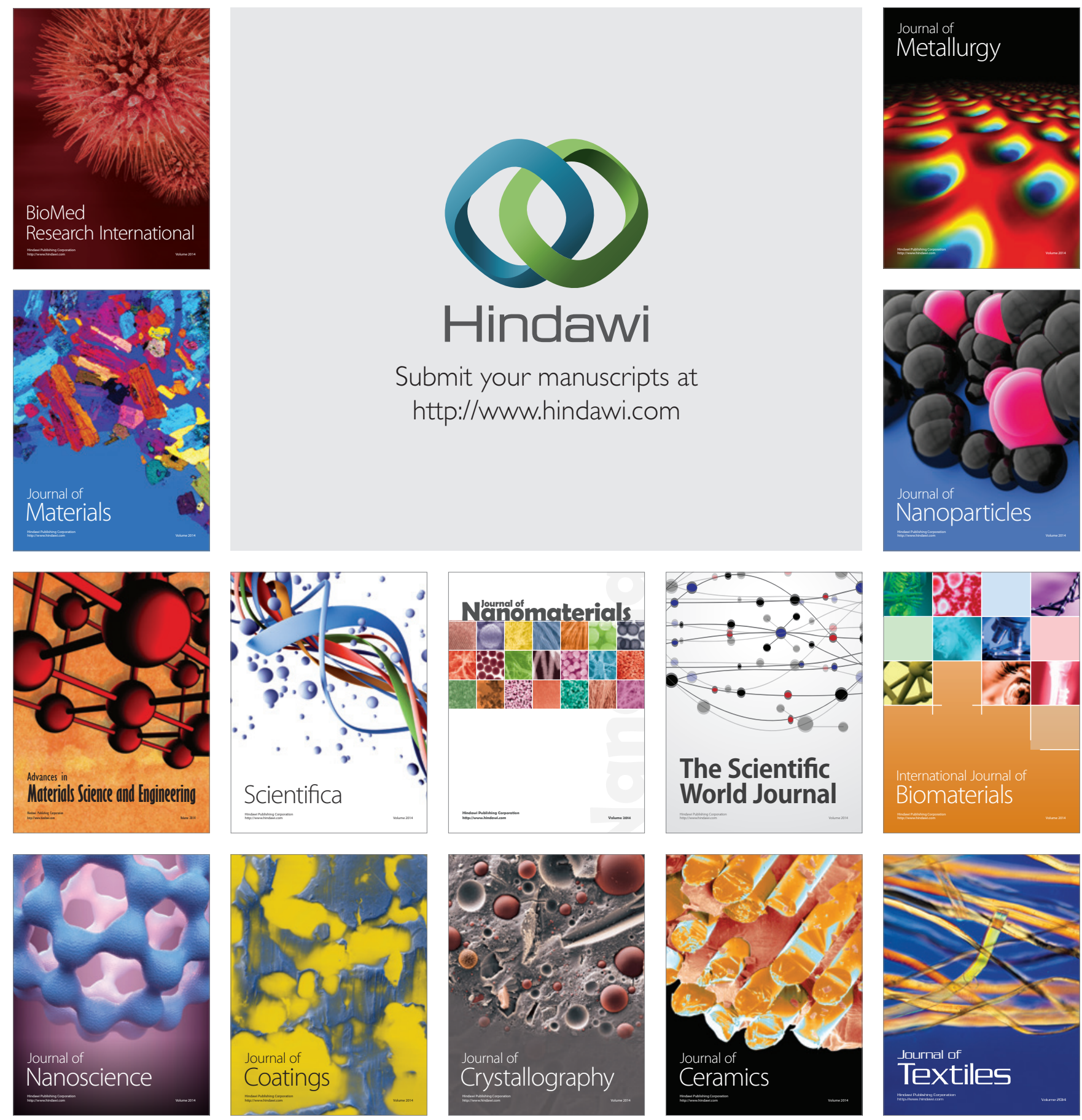